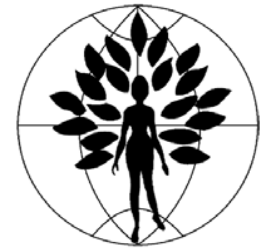

www.figo.org

\title{
Perceptions of pregnancy complications in Haiti
}

\author{
Frank W.J. Anderson ${ }^{a, *}$, Sujata I. Naik ${ }^{a}$, Shingairai A. Feresu ${ }^{b}$, \\ Bette Gebrian $^{c}$, Manju Karki ${ }^{d}$, Sioban D. Harlow ${ }^{\text {e }}$
}

\author{
a Department of Obstetrics and Gynecology, University of Michigan Medical School, Ann Arbor, USA \\ b Department of Preventive and Societal Medicine, University of Nebraska, USA \\ c Haitian Health Foundation, Jeremie, Haiti \\ d United Nations Population Fund, Nepal \\ e Department of Epidemiology, School of Public Health, University of Michigan, Ann Arbor, USA
}

Received 10 January 2007; received in revised form 13 August 2007; accepted 15 August 2007

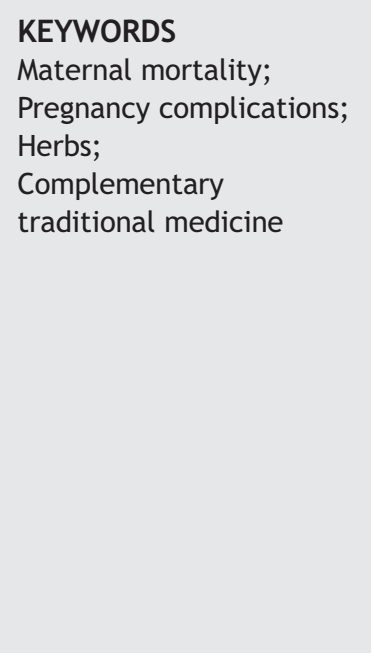

\begin{abstract}
Objective: To determine the incidence of perceived pregnancy complications and associated factors. Methods: During a census, 450 women identified themselves as pregnant and 388 were interviewed postpartum. Results: Complications were reported by $58.6 \%$. Bleeding post-delivery was the most frequent complication $(42.5 \%)$, followed by great pain $(33.8 \%)$, bleeding during pregnancy $(20.1 \%)$, and fever post-delivery $(11.6 \%)$. Prenatal care at either a dispensary or a clinic was associated with reports of bleeding during pregnancy (odds ratio [OR] 9.06; 95\% confidence interval $[\mathrm{Cl}], 1.71-48.00$ and $\mathrm{OR} 7.58 ; 95 \% \mathrm{Cl}, 1.53-37.48$, respectively). Women who visited a doctor were less likely to report bleeding during pregnancy $(\mathrm{OR} 0.20 ; 95 \% \mathrm{Cl}, 0.08-0.55)$ or fever post-delivery $(P=0.015)$. Herb use was associated with reported bleeding during pregnancy (OR 2.22; 95\% Cl, 1.12-4.40) and great pain (OR 1.94; 95\% Cl, 1.05-3.58). Conclusion: The perceived pregnancy complication rate in Haiti is high and is associated with access to health care. The association between use of herbs and pregnancy complications warrants investigation. (C) 2007 International Federation of Gynecology and Obstetrics. Published by Elsevier Ireland Ltd. All rights reserved.
\end{abstract}

\footnotetext{
* Corresponding author. Global Initiatives and Women's Health Division, Department of Obstetrics and Gynecology, University of Michigan Health System, L4001 Women's Hospital, 1500 E. Medical Center Drive, Ann Arbor, MI 48109-0276, USA. Tel.: +1 734615 4396; fax: +1 7347635992 .

E-mail address: fwja@med.umich.edu (F.W.J. Anderson).
}

\section{Introduction}

Pregnancy complications still pose a large and under-realized burden globally. Complications occur in approximately $40 \%$ of pregnancies worldwide, and can be severe in up to $15 \%$ $[1,2]$. Of the 210 million women who are pregnant annually around the world, an estimated 30 million develop pregnancy complications, which are fatal in about 600,000 cases [3]. Hemorrhage, pre-eclampsia and eclampsia, and prolonged or obstructed labor are not only causes of significant

0020-7292/\$ - see front matter ๔ 2007 International Federation of Gynecology and Obstetrics. Published by Elsevier Ireland Ltd. All rights reserved. 
maternal morbidity and mortality, but also contribute to perinatal and neonatal mortality [4-7].

Most of the available data about pregnancy complications in low income countries come from hospital-based data systems, record reviews, or birth logs. Few studies have examined the incidence of obstetric complications in rural communities of poorer parts of the world. In a study of pregnancy complications at the community level, which was nested in a neonatal care trial in India, 772 women were followed prospectively from the seventh month of pregnancy to 28 days postpartum. The most common intrapartum morbidities were prolonged labor, prolonged rupture of membranes, abnormal presentation and primary postpartum hemorrhage; the most common postpartum morbidities included breast problems, secondary postpartum hemorrhage, puerperal genital infections, and insomnia [8].

In a cross sectional study conducted in India, 3600 mothers of preschool-aged children were asked about complications with their last pregnancy. Approximately $10 \%$ reported symptoms of pre-eclampsia, 10\% reported postpartum hemorrhage, and $17 \%$ reported symptoms of infections. Only $57 \%$ of women sought advice or treatment for excessive postpartum bleeding [9].

The present study examined the frequency of perceived complications in a cross-section of pregnant women identified through a population census in the Grand Anse region of Haiti. The overall maternal mortality ratio in Haiti is estimated to be $680 / 100,000$ live births [10]. The Grand Anse region, located in the isolated southwest of Haiti, is thought to have the highest maternal mortality ratio, mostly because of the long distances traveled through mountains and rivers to reach health facilities.

\section{Methods}

This study was conducted in partnership with the Haitian Health Foundation (HHF); this is a private voluntary organization (PVO) that provides both public health and clinical maternal and child health services to the rural regions of Grand Anse in conjunction with the Ministry of Health. Between September and December of 2000, a populationbased census was conducted of all participating villages in the Jeremie County of Haiti in the Grand Anse region, excluding the urban city of Jeremie. At the time of the census 57,930 people were identified, of which 11,489 (20\%) were women of reproductive age. Demographic information was collected, and education and health services were provided. Women of reproductive age (15-49 years) were asked if they were currently pregnant. During the 3-month period, 450 (3.9\%) women of reproductive age identified themselves as pregnant.

The study was approved by the University of Michigan Institutional Review Board, and permission was obtained from the Haitian Health Foundation. Between September and October 2002, as part of HHF programming, an attempt was made to contact the 450 women identified as pregnant during the census to retrospectively determine perceived pregnancy complications and infant outcomes. Sixty-two (13.8\%) women or their families could not be found at follow-up, leaving $388(86 \%)$ that were located and interviewed. None of the women refused to participate. The 6 women who had missing information and 3 women with possible perdition were excluded, leaving 379 women for the analysis.
Community health workers and their supervisors underwent training in the administration of the questionnaire, which had been translated into Creole, translated back into English, and field tested with women who were not participants in the study. Eligible women were located and interviewed at "health posts" (monthly gatherings where vaccinations, prenatal care, and other health services are delivered) or in their homes. If the participant was not able to answer the questions or was deceased, other adult family members were asked to function as proxies. Answers were translated into English and data were double entered.

Each interview lasted 15 to $20 \mathrm{~min}$. Information on demographic and reproductive characteristics, access to service, birth status, obstetric care, and maternal complications was collected. Maternal status (alive/dead) was determined at the time of interview. Age of the mother was calculated from her stated date of birth. Information regarding prenatal care included whether the mother received any prenatal care (yes/no), number of prenatal visits, location of prenatal care (none, dispensary, clinic, rally post, hospital, or somewhere else), and the personnel from whom care was given (none, health agent, nurse, or doctor). Mothers were asked if they were referred to a doctor, by whom (none, health assistant, herself, Gebeau clinic, an idea, or educator), and whether they saw a doctor during the pregnancy. Infant vital status, at birth and at the time of the interview, as well as infant age at time of interview was also obtained. Obstetric information included mode of delivery (vaginal or cesarean), the delivery attendant (traditional birth attendant, nurse, family, or doctor), the place of delivery (home, hospital, or somewhere else), distance from place of delivery to home, and duration of labor. Women were also asked if they used herbs during delivery, whether they perceived any complications (yes/no), and whether they had a bleeding complication, seizures, fever or stuck labor, or other complications.

Descriptive statistics were calculated for perceived complications including bleeding during labor or post-delivery, having a fever during labor or post-delivery, having a tear, and having great pain, as well as for herb usage and infant deaths during the follow-up period. Cross-tabulations of each outcome by each covariate were examined using $\chi^{2}$ tests to assess the strength of the association between outcomes and independent variables. Cross-tabulations between each complication were also examined. Covariates found to be associated in the bivariate analysis were tested in a multivariate model using logistic regression. Odds ratios and $95 \%$ confidence intervals for reproductive and obstetric risk factors were calculated. Data were analyzed using SPSS version 12.0.1 for Windows (SPSS Inc, Chicago, IL, USA).

\section{Results}

The characteristics of the study population are shown in Table 1. Maternal age at the time of the interview was between 16 and 51 years, with a mean age of $32.0 \pm 7.9$. The majority of women (64.6\%) were aged between 21 and 35 years. Most women $(88.2 \%)$ had received at least one session of prenatal care, and nearly $71 \%$ had had at least 3 prenatal care visits. These visits were with someone they described as a nurse (56.5\%). Very few (7.0\%) received prenatal care from someone they described as a doctor. Prenatal care was provided at a rally post (38.8\%), dispensary $(22.4 \%)$, and clinic (26.1\%). Thirty-five percent of women were advised to see a doctor, only half of whom (49.6\%) saw a doctor at least once. 
Table 1 Characteristics of the population

\begin{tabular}{|c|c|c|c|c|c|c|c|c|c|c|c|}
\hline & $\begin{array}{l}\text { Total births } \\
(n=379)\end{array}$ & $\begin{array}{l}\text { Bleed during } \\
\text { labor }\end{array}$ & $\begin{array}{l}\text { Bleed } \\
\text { post-delivery }\end{array}$ & $\begin{array}{l}\text { Fever during } \\
\text { labor }\end{array}$ & $\begin{array}{l}\text { Fever post- } \\
\text { delivery }\end{array}$ & $\begin{array}{l}\text { Great } \\
\text { pain }\end{array}$ & $\begin{array}{l}\text { Used } \\
\text { herbs }\end{array}$ & $\begin{array}{l}\text { Referred } \\
\text { to doctor }\end{array}$ & Stillbirths & $\begin{array}{l}\text { Non stillbirth } \\
\text { deaths }\end{array}$ & $\begin{array}{l}\text { Any child } \\
\text { death }\end{array}$ \\
\hline & $n(\%)$ & $\%$ & $\%$ & $\%$ & $\%$ & $\%$ & $\%$ & $\%$ & $\%$ & $\%$ & $\%$ \\
\hline Total & & 20.1 & 42.5 & 5.0 & 11.6 & 33.8 & 22.6 & 41.0 & 4.5 & 5.0 & 9.5 \\
\hline \multicolumn{12}{|l|}{ Age, years } \\
\hline$\leq 20$ & $31(8.2)$ & 9.7 & 45.2 & 3.2 & 12.9 & 25.8 & 45.2 & 42.9 & 9.7 & 3.2 & 87.1 \\
\hline $21-35$ & $214(56.5)$ & 18.9 & 42.0 & 4.7 & 11.8 & 33.0 & 24.3 & 40.9 & 3.3 & 6.1 & 90.6 \\
\hline$>35$ & $134(35.4)$ & 25.2 & 44.3 & 6.1 & 11.5 & 38.5 & 14.5 & 40.9 & 4.5 & 3.7 & 90.8 \\
\hline \multicolumn{12}{|l|}{ Year of birth } \\
\hline 1971-1986 & $179(47.2)$ & 15.2 & 41.0 & 3.4 & 9.6 & 28.7 & 26.0 & 45.9 & 4.5 & 6.1 & 10.7 \\
\hline $1951-1970$ & $200(52.8)$ & 25.0 & 44.9 & 6.6 & 13.8 & 39.5 & 19.5 & 36.5 & 4.6 & 4.0 & 8.7 \\
\hline \multicolumn{12}{|l|}{ Prenatal visits } \\
\hline None & $40(11.8)$ & 10.3 & 43.6 & 5.1 & 12.8 & 25.6 & 13.2 & 37.1 & 2.5 & 7.5 & 10.3 \\
\hline 1 to 2 visits & $60(17.6)$ & 21.7 & 43.3 & 6.7 & 11.7 & 36.7 & 20.0 & 38.3 & 11.7 & 10.0 & 21.7 \\
\hline 3 to 4 visits & $130(38.2)$ & 24.0 & 45.0 & 5.4 & 14.7 & 37.5 & 21.9 & 41.7 & 3.1 & 6.2 & 9.3 \\
\hline 5 and more visits & $110(32.4)$ & 15.5 & 39.1 & 5.5 & 10.0 & 31.8 & 24.5 & 48.5 & 2.7 & 0.9 & 3.6 \\
\hline \multicolumn{12}{|l|}{ Prenatal location } \\
\hline None & $40(10.8)$ & 10.3 & 43.6 & 5.1 & 12.8 & 25.6 & 13.2 & 37.1 & 2.5 & 7.5 & 10.3 \\
\hline Dispensary & $43(22.4)$ & 20.5 & 37.3 & 4.8 & 7.2 & 28.9 & 19.3 & 74.1 & 2.4 & 3.6 & 6.0 \\
\hline Clinic & $65(26.1)$ & 39.6 & 59.4 & 5.2 & 10.4 & 60.0 & 26.0 & 34.8 & 6.3 & 3.1 & 9.4 \\
\hline Rally post & $64(38.8)$ & 10.5 & 35.7 & 4.9 & 16.1 & 23.1 & 23.2 & 25.0 & 4.9 & 6.3 & 11.2 \\
\hline Elsewhere & $7(1.9)$ & 28.6 & 57.1 & 14.3 & 0.0 & 28.6 & 28.6 & 16.7 & 0.0 & 14.3 & 14.3 \\
\hline \multicolumn{12}{|l|}{ Prenatal provider } \\
\hline None & $12(3.2)$ & 25.0 & 41.7 & 0.0 & 8.3 & 8.3 & 50.0 & 36.4 & 0.0 & 8.3 & 8.3 \\
\hline Health agent & $123(33.2)$ & 12.3 & 33.6 & 6.6 & 11.5 & 28.7 & 24.0 & 46.3 & 4.1 & 6.5 & 10.7 \\
\hline Nurse & $209(56.5)$ & 25.6 & 49.3 & 4.3 & 12.6 & 39.3 & 21.4 & 35.1 & 5.3 & 4.3 & 9.7 \\
\hline Doctor & $26(7.0)$ & 19.2 & 42.3 & 3.8 & 3.8 & 30.8 & 15.4 & 72.0 & 3.8 & 3.8 & 7.7 \\
\hline \multicolumn{12}{|l|}{ Referral Person } \\
\hline Health Personnel & $101(26.8)$ & 12.1 & 34.3 & 5.1 & 6.1 & 29.3 & 19.2 & & 7.0 & 4.0 & 11.0 \\
\hline Other & $31(8.2)$ & 23.3 & 63.3 & 10.0 & 6.7 & 50.0 & 10.0 & & 13.3 & 0.0 & 13.3 \\
\hline None & $245(65.0)$ & 23.4 & 43.9 & 4.5 & 14.8 & 34.6 & 25.6 & & 2.5 & 6.1 & 8.6 \\
\hline \multicolumn{12}{|l|}{ Visited a doctor } \\
\hline No & $167(50.4)$ & 28.9 & 45.2 & 4.2 & 13.9 & 40.6 & 27.4 & 7.2 & 3.0 & 6.0 & 9.0 \\
\hline Yes & $170(49.6)$ & 15.4 & 39.6 & 5.9 & 5.9 & 32.5 & 20.1 & 72.0 & 6.5 & 3.5 & 10.1 \\
\hline \multicolumn{12}{|l|}{ Mode of delivery } \\
\hline Vaginal & $368(98.7)$ & 20.7 & 43.5 & 4.9 & 11.7 & 33.8 & 22.7 & 39.9 & 3.8 & 4.6 & 8.4 \\
\hline Cesarean & $5(1.3)$ & 0.0 & 20.0 & 0.0 & 0.0 & 80.0 & 20.0 & 80.0 & 40.0 & 20.0 & 60.0 \\
\hline
\end{tabular}




\begin{tabular}{|c|c|c|c|c|c|c|c|c|c|c|c|}
\hline Delivery location & & & & & & & & * & & & \\
\hline Home & $359(96.0)$ & 20.1 & 43.5 & 5.0 & 12.3 & 33.5 & 23.0 & 39.6 & 4.2 & 4.7 & 8.9 \\
\hline Hospital & $12(3.2)$ & 25.0 & 25.0 & 8.3 & 0.0 & 50.0 & 8.3 & 72.7 & 16.7 & 8.3 & 25.0 \\
\hline Somewhere else & $3(0.8)$ & 33.3 & 66.7 & 0.0 & 0.0 & 66.7 & 33.3 & 0.0 & 0.0 & 0.0 & 0.0 \\
\hline \multicolumn{12}{|l|}{ Delivery helper } \\
\hline $\begin{array}{l}\text { Traditional birth } \\
\text { attendant }\end{array}$ & $309(82.6)$ & 22.0 & 42.4 & 4.9 & 12.3 & 35.4 & 24.4 & 40.0 & 3.6 & 4.2 & 7.8 \\
\hline Doctor or nurse & $48(12.8)$ & 23.5 & 35.3 & 5.9 & 5.9 & 52.9 & 17.6 & 60.0 & 11.8 & 5.9 & 17.6 \\
\hline Family & $17(4.5)$ & 8.3 & 50.0 & 6.3 & 10.4 & 20.8 & 12.5 & 36.6 & 8.3 & 8.3 & 16.7 \\
\hline \multicolumn{12}{|l|}{ Length of labor } \\
\hline Up to $2 \mathrm{~h}$ & $195(54.5)$ & 17.4 & 41.0 & 5.6 & 10.8 & 26.8 & 19.0 & 35.0 & 4.6 & 2.1 & 6.7 \\
\hline Above 2 to $12 \mathrm{~h}$ & $146(40.8)$ & 20.5 & 43.8 & 4.8 & 15.1 & 38.4 & 25.3 & 49.6 & 4.8 & 7.5 & 12.4 \\
\hline More than $12 \mathrm{~h}$ & $17(4.7)$ & 52.9 & 52.9 & 5.9 & 5.9 & 82.4 & 31.3 & 23.5 & 0.0 & 5.9 & 5.9 \\
\hline \multicolumn{12}{|l|}{ Used herbs } \\
\hline No & $288(77.4)$ & 16.0 & 42.0 & 4.2 & 11.1 & 29.3 & & 44.6 & 5.2 & 5.6 & 10.8 \\
\hline Yes & $84(22.6)$ & 33.3 & 45.2 & 8.3 & 14.3 & 50.0 & & 28.6 & 2.4 & 2.4 & 4.8 \\
\hline \multicolumn{12}{|l|}{ Bleed during labor } \\
\hline No & $298(78.6)$ & & 33.6 & 4.7 & 11.4 & 21.5 & 18.8 & 44.6 & 5.0 & 4.7 & 9.8 \\
\hline Yes & $76(20.1)$ & & 80.3 & 6.6 & 13.2 & 85.3 & 37.8 & 26.4 & 2.6 & 5.3 & 7.9 \\
\hline \multicolumn{12}{|l|}{ Bleed post-delivery } \\
\hline No & $213(57.0)$ & 7.0 & & 3.3 & 8.0 & 19.7 & 21.6 & 40.9 & 5.6 & 3.8 & 9.4 \\
\hline Yes & $161(43.0)$ & 37.9 & & 7.5 & 16.8 & 53.8 & 23.9 & 40.0 & 3.1 & 6.2 & 9.4 \\
\hline \multicolumn{12}{|l|}{ Fever during labor } \\
\hline No & $355(93.7)$ & 20.0 & 40.4 & & 9.3 & 33.3 & 21.8 & 40.0 & 4.2 & 4.8 & 9.0 \\
\hline Yes & $19(5.0)$ & 26.3 & 59.6 & & 57.9 & 52.6 & 36.8 & 50.0 & 10.5 & 5.3 & 15.8 \\
\hline \multicolumn{12}{|l|}{ Fever post-delivery } \\
\hline No & $330(87.1)$ & 20.0 & 40.6 & 2.4 & & 33.6 & 22.0 & 42.1 & 4.8 & 3.9 & 91.2 \\
\hline Yes & $44(11.6)$ & 22.7 & 61.4 & 25.0 & & 39.5 & 27.3 & 25.8 & 2.3 & 11.4 & 86.4 \\
\hline \multicolumn{12}{|l|}{ Had great pain } \\
\hline No & $245(64.6)$ & 4.5 & 30.2 & 3.7 & 10.6 & & 17.1 & 43.2 & 4.5 & 4.9 & 9.4 \\
\hline Yes & $128(33.8)$ & 50.0 & 67.2 & 7.8 & 13.3 & & 33.3 & 36.4 & 4.7 & 4.7 & 9.4 \\
\hline \multicolumn{12}{|l|}{ Mother alive } \\
\hline No & $2(0.5)$ & & & & & & & & 4.6 & 4.8 & 50.0 \\
\hline Yes & $377(99.5)$ & & & & & & & & 0.0 & 50.0 & 9.4 \\
\hline
\end{tabular}


Almost all women delivered at home, with only $3.2 \%$ delivering in a hospital. In contrast to prenatal care, access to delivery care was poor with only $4.5 \%$ of women delivered by a skilled attendant. A traditional birth attendant or family member delivered $82.6 \%$ and $12.8 \%$, respectively. Labor length was self-reported to be between 5 min to $36 \mathrm{~h}$ (mean $248 \pm 4.8 \mathrm{~min}$ ). Consistent with the low frequency of skilled attendants at birth, the cesarean delivery rate was $1.3 \%$. In this population, using herbs during delivery was frequent, with $22.6 \%$ reporting that they had used herbs at some point during labor and delivery.

Both infant and maternal mortality was high. Two women $(0.5 \%)$ died during the pregnancy or follow-up period, one of whose child also died during the follow-up period. A total of 358 women reported a live birth and 36 women reported that their baby was not alive at the time of the interview (101/ 1000 live births).

Some type of complication was self-reported by $58.6 \%$ of women. Bleeding post-delivery was the most frequent perceived complication (42.5\%) and $33.8 \%$ of women reported having experienced great pain (Fig. 1). Tears (4.2\%) and fever during labor $(5.0 \%)$ were infrequently reported complications and were not amenable to further analysis.

The frequency of women reporting a complication during labor differed based on the way the question was asked. Of the women who originally said they did not have any labor complications (46.1\%), 21 women (12\%) subsequently reported having a labor complication when asked about specific symptoms. Of the women who originally said they did have labor complications (53.9\%), 70 women (34.1\%) did not report having any of the complication-specific symptoms.

Many of the perceived complications were associated (Table 1). Bleeding during labor was associated with great pain $(P<0.001)$. Bleeding post-delivery was associated with bleeding during labor $(P<0.001)$, fever during labor $(P=0.009)$, fever post-delivery $(P=0.009)$, and great pain $(P<0.001)$. Fever during labor was associated with fever post-delivery $(P<0.001)$.

In bivariate analysis, prenatal care location $(P=0.004)$ and referral person $(P=0.017)$ were significantly associated with bleeding post-delivery. Women who were referred to visit a doctor $(P=0.051)$ and those who visited a doctor $(P=0.015)$ were less likely to have a fever post-delivery in

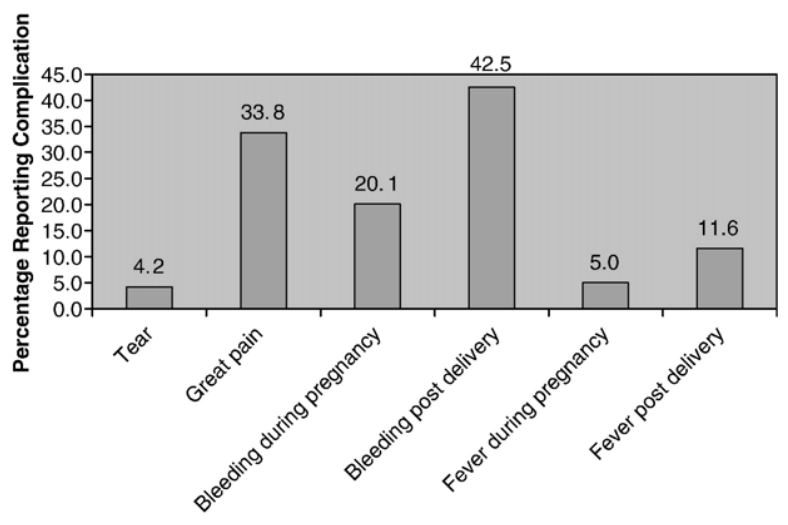

Reported Complications

Figure 1 Frequency of reported complications. bivariate analysis. None of the prenatal care and delivery characteristics factors were associated with fever during pregnancy or after delivery.

Adjusted odds ratios are shown in Table 2. Compared to women born between 1971 and 1986, older women, born between 1951 and 1970, were more likely to report bleeding during pregnancy (OR 2.75; 95\% Cl, 1.40-5.40). Women who received prenatal care at either a dispensary or clinic were also more likely to report bleeding during pregnancy (OR 9.06; 95\% Cl, 1.71-48.00 and OR 7.58; 95\% Cl, 1.53-37.48, respectively). Women who visited a doctor were less likely to report bleeding during pregnancy $(\mathrm{OR} 0.20$; $95 \% \mathrm{Cl}, 0.08-$ $0.55)$. Use of herbs was significantly associated with bleeding during pregnancy (OR 2.40; 95\% Cl, 1.17-4.92).

In the multivariate logistic regression, women who received prenatal care at a clinic were more likely to report great pain (OR 6.60; 95\% Cl, 2.10-20.71) than those who received no prenatal care. Being in labor for more than $12 \mathrm{~h}$ increased the odds of having great pain (OR 13.71; $95 \% \mathrm{Cl}$, 2.65-71.07). Use of herbs was significantly associated with great pain (OR 2.34; 95\% Cl, 1.12-4.88). Bleeding during labor and post-delivery increased the odds of having great pain (OR 12.78; 95\% Cl, 5.43-30.05 and OR 3.63; $95 \% \mathrm{Cl}$, 1.90-6.93, respectively).

Approximately $23 \%$ of women reported use of herbs; herb use was more common in women 20 years and under (OR 6.71; $95 \% \mathrm{Cl}, 2.71-16.61$ ) and in the 21-35 years group (OR 2.18; $95 \% \mathrm{Cl}, 1.19-4.00)$ compared to women older than 35 years. Herb users were more likely to report bleeding in labor than those who did not use them (OR 2.22; 95\% Cl, 1.12-4.40) and great pain (OR 1.94; 95\% Cl, 1.05-3.58). There was no effect of herb use on infant outcome during the follow-up period. Women who were referred to a doctor were more likely not to use herbs (OR 0.43; 95\% Cl, 0.19-0.96).

\section{Discussion}

The Grand Anse region of Haiti is remote and access to emergency obstetric services is poor. The area is typical of a remote rural area in many parts of the world. This study reports the frequency of self-reported pregnancy complications in a rural community setting as determined by interviews of women who delivered an infant after being identified as pregnant during a community-based census.

Bleeding, fever, great pain, and perineal lacerations were the most commonly cited complications of pregnancy and more than half of women in the study reported having at least one complication. There was a significant association between "great pain" and bleeding both during pregnancy and after delivery. As bleeding and great pain were related to prenatal care location, access to care may increase the ability of a woman to recognize pregnancy complications. Women who perceive these symptoms may also be more likely to seek care at a particular location relative to those without the symptoms. Prenatal care location and provider were associated with referrals to doctors, and visits to doctors were associated with fewer reports of complications; however, less than half of the referred women visited a physician. This finding suggests an effective referral system, when utilized, is an important and potentially effective part of a maternal health program. 


\begin{tabular}{|c|c|c|c|c|c|c|c|}
\hline & Bleed during labor & Great pain & Used herbs & Referred to doctor & Stillbirths & Non stillbirth deaths & Any child death \\
\hline & Adjusted OR $(95 \% \mathrm{Cl})$ & Adjusted OR (95\% Cl) & Adjusted OR $(95 \% \mathrm{Cl})$ & Adjusted OR $(95 \% \mathrm{Cl})$ & Adjusted OR $(95 \% \mathrm{Cl})$ & Adjusted OR $(95 \% \mathrm{Cl})$ & Adjusted OR $(95 \% \mathrm{Cl})$ \\
\hline \multicolumn{8}{|l|}{ Total } \\
\hline Age, years & & & $* * *$ & & & & \\
\hline$\leq 20$ & & & $6.71(2.71-16.61)$ & & & & \\
\hline $21-35$ & & & $2.18(1.19-4.00)$ & & & & \\
\hline$>35$ & & & Reference & & & & \\
\hline Year of Birth & $* * *$ & & & & & & \\
\hline $1971-1986$ & Reference & Reference & & & & & \\
\hline $1951-1970$ & $2.75(1.40-5.40)$ & $1.87(0.99-3.54)$ & & & & & \\
\hline \multicolumn{8}{|l|}{ Prenatal visits } \\
\hline None & & & & & Reference & Reference & Reference \\
\hline 1 to 2 visits & & & & & $0.28(0.03-2.52)$ & $2.55(0.39-16.54)$ & $0.30(0.08-1.23)$ \\
\hline 3 to 4 visits & & & & & $0.86(0.09-8.05)$ & $1.22(0.21-6.96)$ & $0.75(0.19-2.94)$ \\
\hline 5 and more visits & & & & & $1.87(0.16-22.19)$ & $0.21(0.02-2.70)$ & $2.91(0.52-16.26)$ \\
\hline Prenatal location & $* * *$ & $* * *$ & & & & & \\
\hline None & Reference & Reference & & Reference & & & \\
\hline Dispensary & $9.06(1.71-48.00)$ & $0.99(0.28-3.54)$ & & $3.90(1.04-14.67)$ & & & \\
\hline Clinic & $7.58(1.53-37.48)$ & $4.57(1.29-16.20)$ & & $2.67(0.65-10.95)$ & & & \\
\hline Rally post & $0.56(0.12-2.59)$ & $0.83(0.27-2.57)$ & & $3.12(0.87-11.13)$ & & & \\
\hline Elsewhere & $3.14(0.21-47.09)$ & $1.12(0.09-13.38)$ & & $0.23(0.02-3.05)$ & & & \\
\hline \multicolumn{8}{|l|}{ Prenatal provider } \\
\hline None & Reference & Reference & & Reference & & & \\
\hline Health agent & $1.70(0.17-17.27)$ & $26.68(1.89-377.17)$ & & $3.47(0.54-22.20)$ & & & \\
\hline Nurse & $1.74(0.19-16.08)$ & $16.73(1.27-220.69)$ & & $1.87(0.33-10.75)$ & & & \\
\hline Doctor & $1.84(0.15-21.95)$ & $18.65(1.00-348.19)$ & & $2.04(0.27-15.44)$ & & & \\
\hline \multicolumn{8}{|l|}{ Referral Person } \\
\hline Health Personnel & $0.54(0.19-1.57)$ & & & & $0.36(0.09-1.37)$ & & \\
\hline Other & $1.01(0.31-3.25)$ & & & & $0.20(0.04-0.88)$ & & \\
\hline None & reference & & & & reference & & \\
\hline Visited a doctor & $* * *$ & & & $* * *$ & & & \\
\hline No & Reference & & & Reference & & & \\
\hline Yes & $0.20(0.08-0.55)$ & & & $40.09(15.40-104.35)$ & & & \\
\hline Mode of delivery & & N/A & & & * & & * \\
\hline Vaginal & & $\mathrm{N} / \mathrm{A}$ & & & Reference & & Reference \\
\hline Cesarean & & N/A & & & $0.03(0.00-0.74)$ & & $0.5(0.00-0.84)$ \\
\hline
\end{tabular}




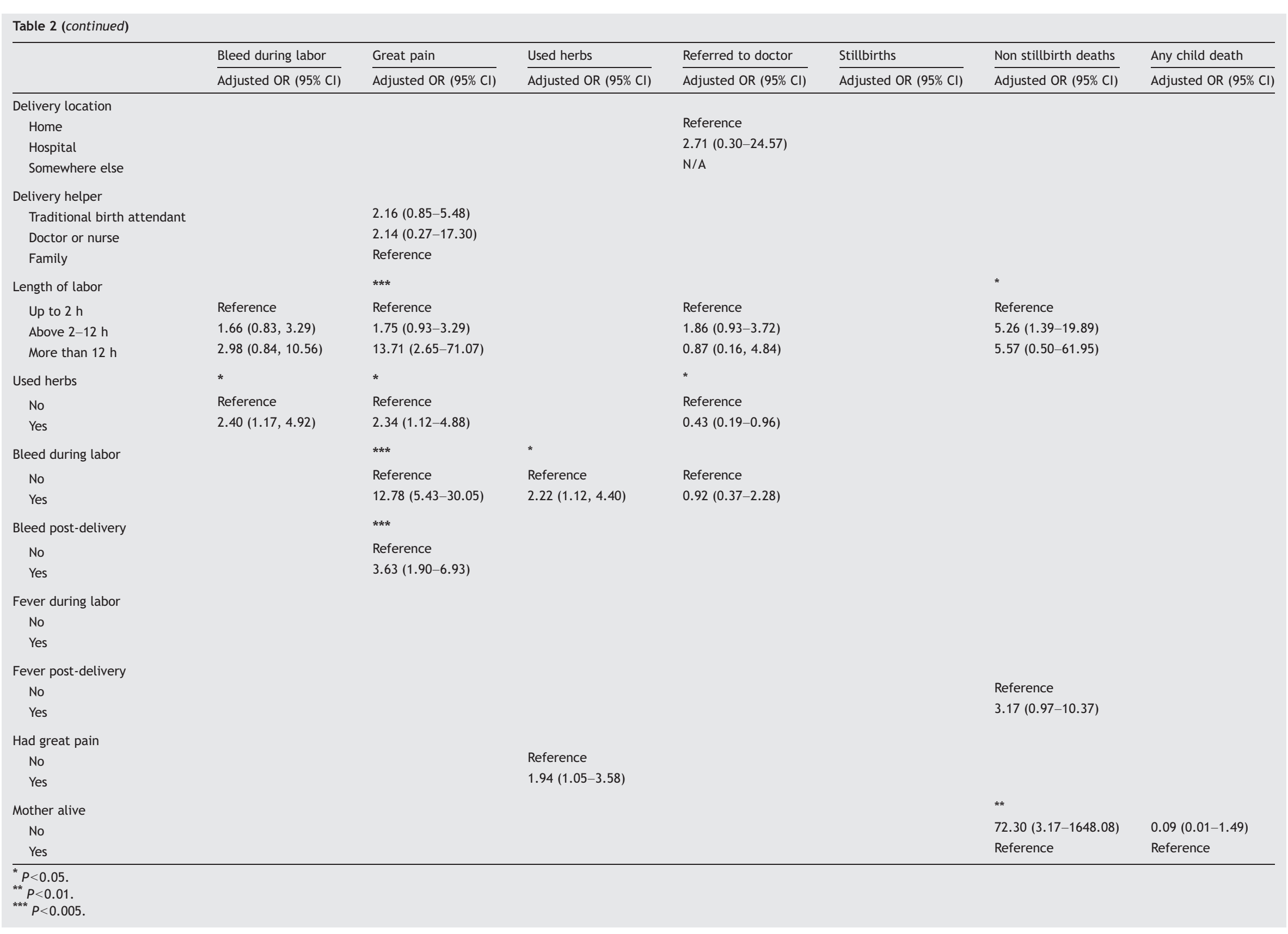


There was a notably low cesarean delivery rate $(1.3 \%)$ among participants in this study. This rate is similar to that found in the Haiti Demographic and Health Survey of $0-1.1 \%$ in various regions [11]. High maternal mortality exists in areas with low cesarean delivery rates and indicates a lack of access to emergency obstetric care.

The association of the use of herbs and bleeding and pain during pregnancy is an important finding. The use of herbs in rural settings in low income countries is assumed to be common. For example, $80 \%$ of the population of Africa uses a traditional medicine for health care [12]. In this study, $22.6 \%$ of women used herbs at some point during labor. Further investigation into the cultural aspects of herb use with qualitative methods and bench research in the uterotonic potential of commonly used herbs is necessary to fully understand risks and potential benefits of herb use in rural regions.

The associations found in this study do not necessarily represent causality. Further research will be required to determine how knowledge of these associations can be used to improve maternal care programs in rural communities. Obstructed labor and pre-eclampsia/eclampsia were not detected through this survey. Further studies are needed to define ways to identify these complications at the community level. The interview results represent the perceptions of the participants. Validation of pregnancy complication responses at the community level would be necessary to determine the severity of the reported complications. Clinical information about the cause of deaths was also not available, as most of the deaths occurred in the home without further investigation. Maternal mortality reviews and near miss investigations are now being conducted in this region to identify areas of intervention. The use of a population-based census decreases selection bias and allowed for a follow-up rate of $86 \%$, which is high for a rural population and indicates a low rate of out migration for women who have recently delivered. The $14 \%$ lost to follow-up rate is low, and no further information is available for that group.

From this study, it is evident that the rate of perceived complications is high. Perception of complications seems to increase when the patient has access to the health care system. The association of herb use and pregnancy complications warrants further study. In the global effort to reduce maternal mortality, community level recognition and initial treatment of pregnancy complications is necessary to reduce the chance that complications progress to untreatable levels.

\section{Acknowledgements}

The authors would like to acknowledge the Haitian Health Foundation (HHF) for allowing us to partner with them.

\section{References}

[1] UNICEF, WHO, UNFPA. Guidelines for monitoring the availability and use of obstetric services. New York: UNICEF; 1997.

[2] Wardlaw T, Maine D. Process indicators for maternal mortality programmes. In: Berer M, Sundari T, editors. Safe motherhood initiatives: critical issues, reproductive health matters. Oxford: Blackwell Science; 1999. p. 24-30.

[3] World Health Organization. The World Health Report 2002: reducing risks, promoting healthy life. Geneva: World Health Organization; 2002.

[4] Anonymous. Healthier mothers and babies. Morb Mort Wkly Rep 1999;48:849-58.

[5] Katz J, West Jr KP, Khatry SK, Christian P, LeClerq SC, Pradhan EK, Shrestha SR. Risk factors for early infant mortality in Sarlah District, Nepal. Bull World Health Organ 2003;81:717-25.

[6] Kusiako T, Ronsmans C, Van der Paal L. Perinatal mortality attributable to complications of childbirth in Matlab, Bangladesh. Bull World Health Organ 2000;78:621-7.

[7] Marsh DR, Darmstadt GL, Moore J, Daly P, Oot D, Tinker A. Advancing newborn health and survival in developing countries: a conceptual framework. J Perinatol 2002;22:572-6.

[8] Bang RA, Bang AT, Reddy MH, Deshmukh MD, Baitule SB, Filippi V. Maternal morbidity during labour and the puerperium in rural homes and the need for medical attention: a prospective observational study in Gadchiroli, India. BJOG 2004;111:231-8.

[9] Bhatia JC, Cleland J. Obstetric morbidity in south India: results from a community survey. Soc Sci Med 1996;43:1507-16.

[10] World Health Organization. Maternal Mortality in 2000: estimates developed by WHO, UNICEF, UNFPA. Geneva: World Health Organization; 2004.

[11] Stanton CK, Dubourg D, De Brouwere V, Pujades M, Ronsmans C. Reliability of data on caesarean sections in developing countries. Bull World Health Organ 2005;83:449-55.

[12] World Health Organization. WHO traditional medicine strategy 2002-2005. Geneva: World Health Organization; 2002. 